\title{
A MATTER OF TOLERANCE
}

TECTONICS

\section{GENEVIEVE BAUDOIN}


ABSTRACT - Tolerance lies at the crux between the contingencies of context and autonomous production. The problem of detailing lies, in part, on understanding that the detail, from its representation to its actualization, is the architecture: tolerance is what transpires in the transformation. It is a byproduct of the disciplinary autonomy of architecture that is created out of understanding contingency: designing with it is the making of architecture. The whole is no thing without its parts.

Historian Kenneth Frampton discusses "tectonics" as a series of opposites, particularly between the "ontological" and the "representational." The design of details is thus suspended between what it "is" and its appearance. What is crucial to consider in this relationship is that the construction of those details must be designed in any work of architecture. In the translation from drawing to built work, the design must accommodate reality: the imprecision of equipment, humans, materials, and site. The literal gaps given over to "reality" are what we understand as tolerances.

Tolerance exists between the lines of a drawing, but it is virtually the only way to ensure a building can be created on site. It can also be seen as something outside the control of the architect - a building is contingent on the tolerances supplied by manufacturers and agreed upon with contractors. The gymnastics of designing for or with tolerance is typically done behind the scenes so that the representation of the building (idea) and the building (form) appear the same.

This essay will explore architects with a particular insight into tolerance, and who seek to maintain control of the parameters of variability inherent to the design of construction through details. The work of architects including SHoP, Kieran Timberlake, and Frank Gehry will be considered for their attitude towards and understanding of the nature of tolerance. Their work will be studied from built object back through the design process, examining the ways in which tolerance is tied to tectonic expression, where the parts (and what lies between them) facilitates the whole.

Keywords: contingency, detail, tectonics, tolerance

In the translation from drawing to building, there exists an area of contingency inside the space of every line drawn. This space leaves room for the interface of trades and the unforgiving (and occasionally mischievous) nature of building materials. Concrete slumps, wood bows, and steel expands and contracts in the changing temperatures of the day. Humans very rarely draw in straight lines, and "apparent" straightness is more an optical illusion than a reality built from geometry. We also very rarely build in single materials (caves are perhaps the exception). Because of this, the design of buildings must confront the ways in which the materials of construction join together, how they age, and how they move independently of one another. This is also the moment where architecture ceases to maintain its disciplinary autonomy - tolerance 


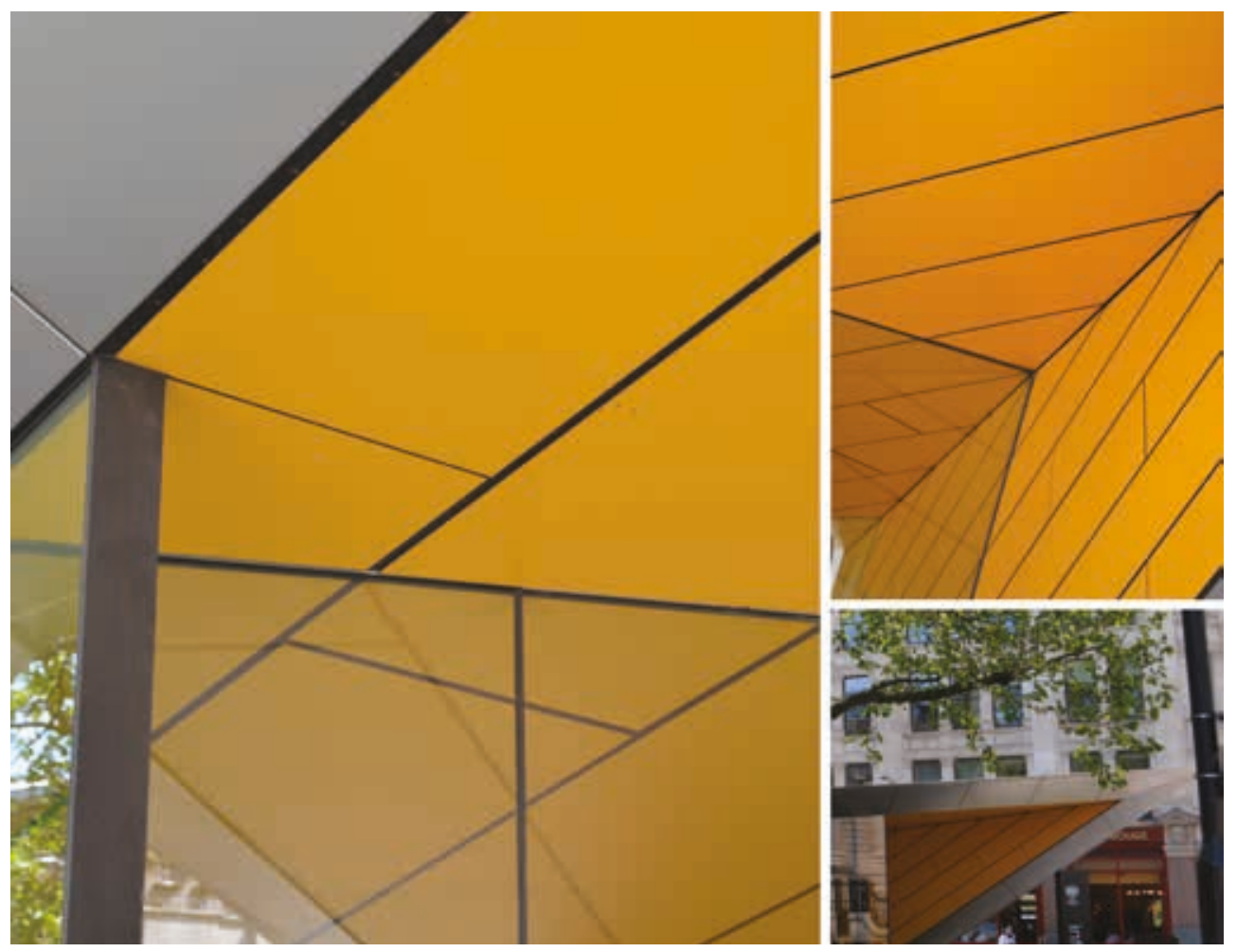

Figure 1. Apparent straightness. Make Architects, City of London Information Centre, 2007.

forces the architect to contend with the contingencies of the builders and materials. It is where the designer controls the uncontrollable, and why it is so significant to the discipline of architecture. (Fig. 1)

\section{ON TOLERANCE}

Tolerance is the deviation we allow for human (and machine) error in installation and in the creation of the parts that create a building. As with statistics, tolerance is an allowable deviation from the precision of a drawing that will allow a building to "fit" together. While tolerances have improved (read: reduced) with the industrialization and manufacture of materials, humans are still involved in the installation of components on site. The assembly of these components is fundamentally contingent on the various workers installing each piece of the building in the right location, the location being where it is intended to be on site, and each piece must be manufactured or cut to the dimensions in a drawing either off or on site. This is essentially impossible to control to perfection - in the field of mathematics, there are theorems ${ }^{1}$ that demonstrate that we will only ever be able to get infinitely close to zero. Despite our innovations with robotics and BIM technologies, we will only be able to reduce tolerances, not eliminate them.

The act of Architecture exists in both drawing and building, but a building cannot be built without understanding tolerances, even though tolerance 
is typically something that is never "represented" in a drawing. This is the reason why Vittorio Gregotti states, "... [it is] false to think that culture of industry or building...could solve the problem of detailing; this might be convenient or economic to the architect, but lead to the unprecedented downfall of architecture." 2 The problem of detailing lies, in part, on understanding that the detail, from its representation to its actualization, is the architecture: tolerance is what transpires in the transformation. Where tolerance shows up, and where it becomes an active player on the stage that is architecture, is in the way details are designed to cope with tolerances. This design knowledge is rarely if ever taught in school, and only an architect that has had to face the dilemma of trades and/or materials coming together in an unfortunate manner will really begin to tackle designing with tolerances. This issue is also at the heart of what we consider the "tectonics" of architecture - it is the way we design the joints in a building because we cannot build in single monolithic materials.

For the purposes of this paper, it is critical to understand that architecture is not a simple assemblage of parts. Kenneth Frampton, discussing the etymology of the word, "tectonics" in Studies in Tectonic Culture, describes the history of the word's origins from that of tekton: "...the role of the tekton leads eventually to the emergence of the master builder or architekton. That...term would eventually aspire to an aesthetic rather than a technical category.... 'Tectonics becomes the art of joinings." " ${ }^{3}$ From the master builder idiom, tectonics in architecture grows to become both the act and art of joining. With advances in manufacturing technologies and digital interfacing, it is now possible to go from the drawing of a building to its built form with a relatively simple selection of standard parts, as long as the drawing only employs standard details. This is the way manufacturers such as Butler or Tuff Shed have made great strides in both speed and efficiency in construction. In architecture, however, there is always a level of experimentation either in the way things are meant to go together, or in the way things are meant to look. This typically means that a piece of architecture is an amalgam of standard details and designed details - the components of the building are also not always assembled in a "standard" way. Therefore the architect must rely on either their own understanding of the tolerances at stake in a project, or they must be able to work with the manufacturer to understand and design for them. There are two approaches of interest that architects take to tolerance in the translation between drawing and building. The first approach to tolerance is to acknowledge the issues created by both materials and installation in designed details with the appearance of precision. The second approach to tolerance is to refuse to accept contractor or manufacturer standards and attempt to precisely control the installation and manufacture of the components of a building, either through early interfacing with a manufacturer, or by taking on the role of manufacturer or installer on a building project.

The first approach - designing details with the appearance of precision - is the way in which most architects work. By designing details, both standard 
and particular to a project, in a way that allows the materials to appear to come together in a precise way, there is room to play. This typically occurs by considering the ways the layers of a detail "lap" over each other, or by the ways in which they are held apart (the "shadow gap"). For instance, consider a structural column in an interior space. The column is often clad to provide fireproofing, or to disguise either the potential misalignments that may have occurred when the column was put in place or the general appearance of the underlying structure. The flooring is most typically not the literal structure, but a layer on top of the structure - the cladding of the column can be designed to easily hide the interface of the flooring with the column. The same is true of the ceiling. While the scenario described above may appear at first glance as a way of coping with shoddy construction, an architect designing for this detail may be considering much more. Earthquake movement, live loads, floor cleaning, the tactility of the column, durability, integrated systems, the way the column interfaces with other objects in the space: all of these and more may be at the heart of an architect's decision to detail a column in a space in a particular way. These details are as important to the overall project as the form is to the site.

The second approach - attempting to control tolerances - has been of particular interest to architects designing with complex forms or invested in the design of the manufacture of the components of building. While all architects may be concerned with controlling tolerances to a certain level, the methods of digital modeling (including BIM technologies and parametric modeling) have become sophisticated and compelling enough tools to create the possibility to demand complete control over tolerance. This approach is of particular significance because it seeks to eliminate, through detailing, what necessitates detailing in the first place. Without tolerance, architecture could be a matter of designed assemblage, without the interface and expertise of contractors or manufacturers. This could radically transform what architecture is - but, by giving architects ultimate control over tolerance (and essentially construction), will this propel architecture into something new? Are BIM technologies and parametric modeling going to actually change the way in which we detail, and does this reflect a return to autonomy in architecture?

\section{BIM, PARAMETRICS, AND DETAIL DESIGN}

Kieran Timberlake founded their practice by promoting the industrial model of innovation and integration found in parallel industries for architectural practice - this can be seen most clearly in their book Refabricating Architecture, where they argue that as architects we must again be the master builder: "Today's master architect is an amalgam of material scientist, product engineer, process engineer, user and client who creates architecture informed by commodity and art." ${ }^{4}$ This is in part to ensure the 
quality of the construction and its efficient assembly on the site, and in part to "re-design" the way architects actually design and deliver buildings. By using BIM technologies, "The greatest discovery has been the resurrection of our ability to control craft." 5

Kieran and Timberlake's Loblolly House, built in 2006, is an archetypal example of their approach to BIM technologies and their efforts to control tolerances. There are three larger components to the design as it was translated to the site: the foundation system, the framework, and the infill panels. The framework and infill panels were all produced off-site under controlled conditions and preassembled in the factory before being brought to the site. The framework is entirely aluminum track with components that slide and notch into this track system to bolt together the frame. Because the frame is entirely aluminum, a single manufacturer was responsible for ensuring the tolerances of the members and the precision with which the frame could be put together. Its tolerance is extremely low. The prefabricated infill panels were designed to lock into this framework, and are designed with the understanding that the initial frame will be extremely precise. ${ }^{6}$

The foundation consists of a series of straight and leaning piles that support a large wooden base frame that was assembled on site. While some of the piles were installed as much as two feet off of their drawn placement, the platform serves to absorb all of these tolerances and ensure that the aluminum frame can simply rest on top of its wooden platform. ${ }^{7}$ What is interesting about this project is not the ways in which they have chosen to tackle the issue of control on site, but the ways in which they have chosen to design (and accommodate) the prefabricated assembled parts through on-site fabrication and assemblage. The components are not quite like an ERECTOR set ${ }^{8}$ where every fastener has been left exposed to reveal the way in which it was assembled. The components are also not entirely seeking to hide the method of assembly that was used to create the building. The details have been carefully designed to look like an aluminum frame with infill panels. But the house is also entirely resting on a site-built wooden raft that absorbs all site and installation tolerance without revealing the connection details. While great effort has been expended to reveal the "kit of parts" nature of the aluminum frame, flaunting the precision of the pre-assembled parts, the houlies at the opposite end of typical tolerances on a site. (Fig. 2)

Architect Frank Gehry's office pioneered the use of digital tools as a way of directly translating three-dimensional models into full-scale digital replicas that could be outputted through direct fabrication - this can be seen particularly in his design of the Barcelona Fish for the Olympics in 1992. His models build in "material resistance" ${ }^{9}$ through the use of paper and other sheet materials that can imitate the intended materials to be used: "One of the ways Gehry focuses on the building is by translating the 


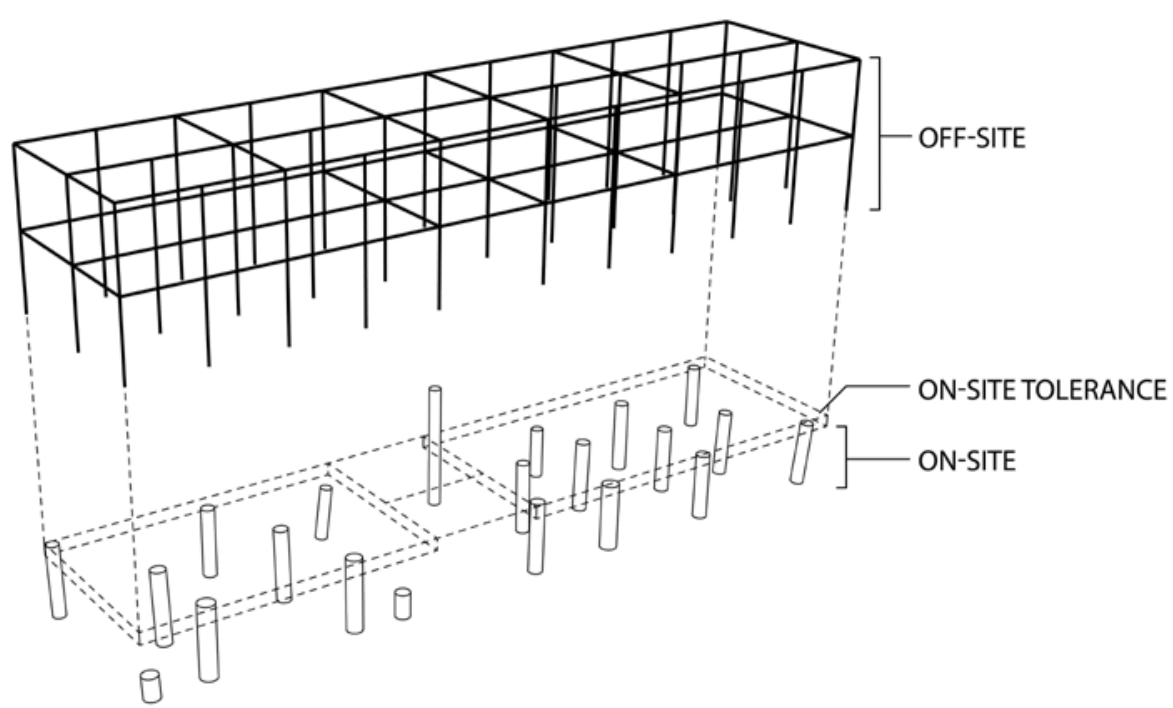

Figure 2. Diagram of off-site vs. on-site tolerances in Kieran Timberlake's Lobolly House, 2006.

drawing into a physical model. This crucial step relates the drawing to the 'logic' of construction missing in the sequence [from drawing to building]." 10 Once the model was complete, the office looked to their new recruit, Rick Smith, from the aeronautics industry, to translate this model to CATIA: “... [the] digital model was used to directly generate a laser-cut paper stack model that was compared to the original physical model in order to verify the accuracy of the translation. It matched." ${ }^{11}$ From there, the model was developed into a digital skin and structure and attachment points for the skin could be determined through the model and in built form. This "skinin" 12 approach is similar to automotive manufacturing by offsetting the skin from the frame for tolerance issues - this allows the skeleton to be built and the skin applied at a certain offset that allows for adjustments as needed to preserve the smooth appearance of the skin. (Fig. 3) This method used to construct the Barcelona Fish has become the basis for the translation process from model to building for all of the Gehry's work that has come since, including the Los Angeles Philharmonic and the Guggenheim Bilbao. (Fig. 4)

For Gehry's office, the digital tools used for these projects enable the actualization of complex three-dimensional shapes - these are not specifically intended to reduce tolerances but to achieve construction at all in a timely manner. Control over the complexity of the form is accomplished, as is buildability, but typically these projects still rely on a lapped or shingled approach to the cladding to allow for tolerances within the skin. This is also in part because of the vast scale change from an automobile to an art museum - metal will expand and contract more over a greater surface area. The design of the actual details for the metal cladding on each of their projects relies on their interface with the manufacturers - the detail is not itself produced by the digital technologies 


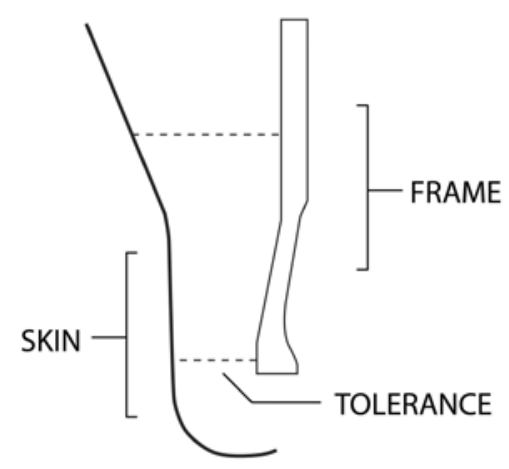

AUTO INDUSTRY

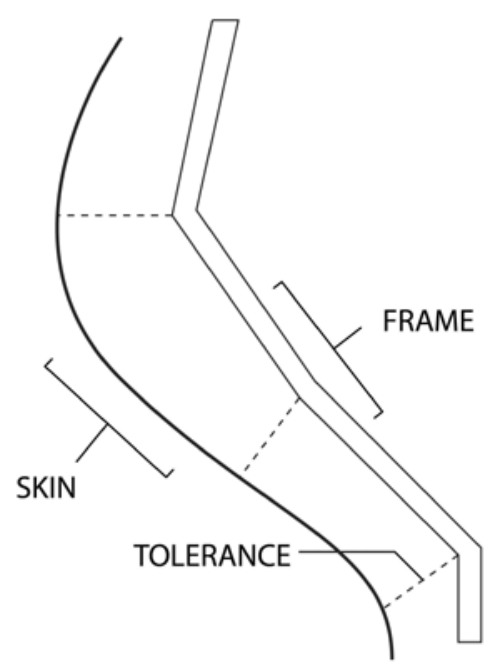

GEHRY CLADDING

Figure 3. Diagram of skin-in approach in Frank Gehry's approach to cladding.

used to represent it, and tolerance for these complex shapes is critical to preserve. While the skin itself can appear smooth, designed tolerances are accounted for behind and within the skin. (Fig. 4)

SHoP Architects, like Kieran and Timberlake, see the potential of BIM technologies to allow greater control for the architect over the "craft" of

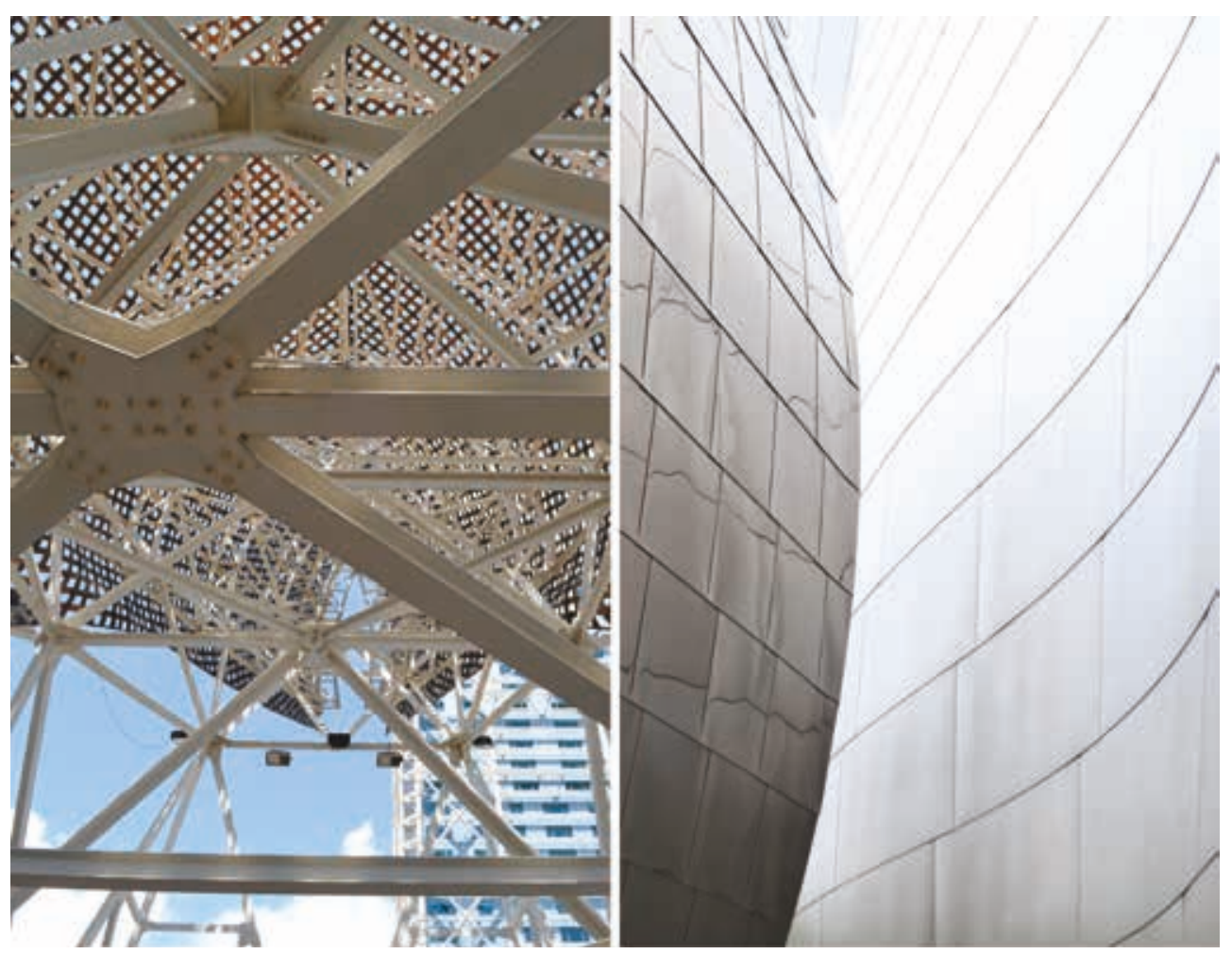

Figure 4. Similar approaches to cladding. Frank Gehry Architects, Barcelona Fish, 1992 (left), Los Angeles Philharmonic, 2003 (right). 
building, including both design and tolerance: "SHoP adapted BIM from the world of engineering and incorporated it fully into the office workflow.... leading in this new area, and in what the partners have come to call 'direct fabrication'... has allowed SHoP to conduct itself in a manner closer to the master builder mode...." ${ }^{13}$ Their work with BIM technologies has pushed their firm into a being both architect and contractor, often working as a design-build service. From their PS1 installation, Dunescape, completed in 2000 , to their larger built work, the firm works closely not only with manufacturers but on site during installation: "...the only drawings issued for the building were diagrams that resemble instructions for putting together a plastic model.... No measuring, no cutting, no ambiguity: control." 14

The Porter House project, completed in 2003, helped establish a methodology for the firm focusing on specific designed complexities of the project, deriving detail solutions that are customized for the particular project. Differing from Kieran Timberlake, SHoP does not necessarily rely specifically on innovating existing manufactured details (like those seen in the Loblolly House). Instead, the Porter House cladding, similar to the methodology that created Dunescape, is designed to specifically accommodate an extensive variety of widths using an identical spacing between panels, as well as specific "other" conditions such as windows and corners:

"The pattern was calibrated to make the most efficient use of standard sheets of zinc. We worked closely with the fabricators to understand the properties of the material and the parameters that defined its manipulation. Each panel was laser-cut directly from our digital files and etched with a reference code that was keyed to installation drawings, which indicated location of panels, sequence of installation, and special instructions such as flashing details and mock-up requirements." ${ }^{15}$ (Fig. 5)

Similar to Gehry, their efforts in managing the transition to construction is designed in part to make the project at all buildable. The number of different panel types on the Porter House would be daunting and costprohibitive without the "paint-by-number" strategy designed into the cladding system. As with Gehry, SHoP's approach to the spacing between panels is not derived by the digital modeling program used to fabricate the cladding, but the tolerance and spacing is critical to making the project quite literally come together.

\section{CONCLUSIONS}

These architectural practices have all used parametric modeling or BIM technologies to maintain control over the built outcomes of their designs. 


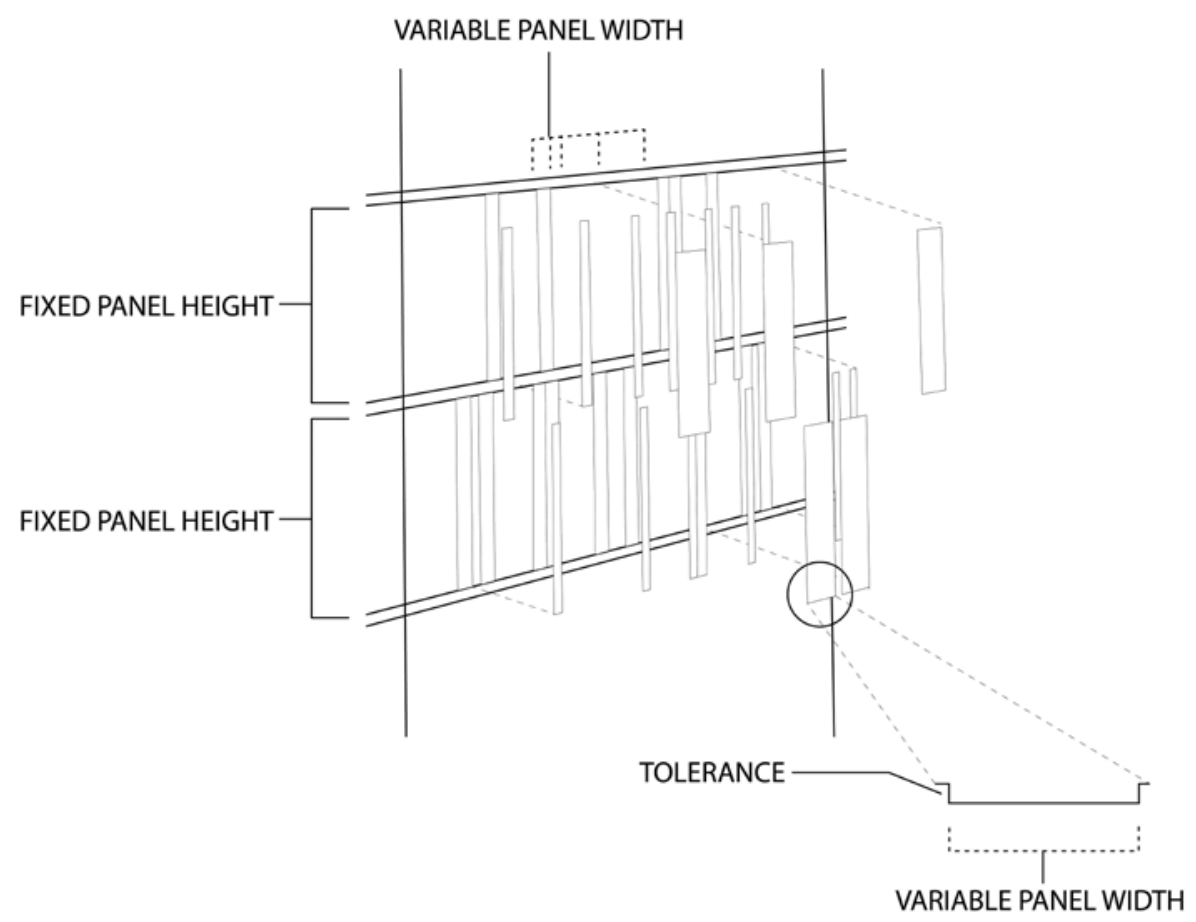

Figure 5. Diagram of customization and standardization in regards to tolerance in SHoP Architects' Porter House, 2003.

Regardless of their differing goals and radically distinct project types, there are potentially two key aspects worth discussing in relationship to tolerance and the design of details. The first is that these digital modeling methods can be a kind of foil for interfacing with manufacturers and builders, allowing the architect to use the detail design as a way of driving whole architectural projects. Francesca Hughes writes on the Architecture of Error, "Architectural practice is all about serial translation and serial approximation, whose action must nonetheless remain invisible if it is to serve up the seamless correspondence between idea and form, drawn or built, it promises." ${ }^{16}$ The gymnastics of designing for or with tolerance is typically done behind the scenes so that the representation of the building (idea) and the building (form) appear the same. What is interesting about these three practices is that the correspondence between idea and form are directly informing each other so that tolerance no longer has a back stage presence. The interface of the digital medium allows for the design for tolerance to be an integral part of not only the representation of the building but fundamental to the design of the building.

The second aspect to consider is that regardless of the digital interface, the actual design for tolerance is not designed in that digital interface. Said another way, designing for tolerance is not simply accounted for within parametric or BIM modeling. Dan Willis and Todd Woodward, discussing this dilemma, describe the process of generating an "exact" and accurate digital replica that require gaps to account for "errors" in production and assembly, such as paint and varnish: 
"These artificially defined gaps, which facilitate the precise computer-controlled fabrication of building elements and allow for their assembly in an imprecise world, require the judgment of an architect or building expert. We believe the inevitable 'errors' present in reality, including natural processes such as thermal expansion and weathering, make it impossible to achieve a direct correlation between digital data and a constructed building. Interpolation, based on an understanding of construction tolerances, material behavior, and the ergonomics of building assembly, will always be required." 17

Returning to Gregotti's sentiment, the problem of detailing will not be solved by the building industry or by the increasingly sophisticated ways in which we can simulate a digital version of the built outcome. The simulation will never erase the need for tolerance, or the need to design ways in which to hide or take advantage of these errors.

An intriguing avenue in design is created by using the "slippage" created in the translation from BIM or parametric modeling strategies to built objects. Nader Tehrani, writing on his "edge" project explored at the Graduate School of Design, at Harvard, describes one such approach: "We designed a panel to allow for a small tolerance of slippage between the individual units, and also to permit an overall form with indefinite edges - a concept that allowed our prototype the possibility of being part of an extended system." ${ }^{18}$ Where this project breaks from those discussed in the paper is the way in which the detail is designed first without a complete understanding of the potential whole. While the Loblolly House structure and infill panels, the Porter House cladding, and Gehry's skin-in metal cladding can all be reimagined into different forms without losing the detailing methodology or approach to tolerance, it is intriguing to think through the design of a detail (from the initial cell and its connection to the next) leaving the eventual application open-ended. While both strategies depend on the overall result and agglomeration, tolerance for Tehrani's project becomes critical to the buildability of the end result through the looseness of the connections, not an increasingly precise control.

The benefit of examining these types of projects does not necessarily derive from their ability to reduce tolerances, nor is it because of the power of BIM and other direct fabrication technologies. These projects are interesting because of the knowledge of tolerance in detailing that is necessary in spite of their interest in reducing tolerances or use of BIM/ direct fabrication technologies. The paneling produced for the façade of the Porter House is interesting because of their economic use of zinc sheets, but the paneling is a powerful design because the form of the Porter House can change and the panels would still accommodate the form. The panels are also designed with an overlapping fold that builds in a shadow gap between panels and adds strength to each component. 
Gehry's skin-in approach allows him to create exuberant forms, but it also gives him a flexible installation strategy using lap joints to selfcorrect. Again, the form could be substantially different but the design of the installation system will remain - that design is the strength of the project. Kieran Timberlake's Loblolly House is not an advancement in prefabricating houses, but the kitbashed details that generate the House (modified from standard Alcoa framing) creates another system of details that could generate an entirely different house with the same parts. By eliminating all site tolerances in one move with the platform on which the house sits, the detail of the transition from wooden platform to aluminum frame allows the project to be built, again with a system that could accommodate different forms. All of these projects are not necessarily stronger by the use of BIM or parametric technologies: their design strengths lie outside of these programs and in the ways the architects have made impossible or potentially impossible to build projects buildable - not with a paint by number system at installation, but with a strong design knowledge of the way the components are intended to fit together. The details are the design of the project. 


\section{Notes}

1 Such as Richardson's Theorem or the Constant Problem.

2 Vittorio Gregotti, "The Exercise of Detailing", 1983, in Kate Nesbitt, ed., Theorizing a New Agenda for Architecture: An Anthology of Architectural Theory 1965-1995, (New York NY, USA: Princeton Architectural Press, 1996), 497.

3 Kenneth Frampton, Studies in Tectonic Culture: The Poetics of Construction in Nineteenth and Twentieth Century Architecture, ed. John Cava (Cambridge MA, USA : MIT Press, 1995), 4.

4 Stephen Kieran and James Timberlake, Refabricating Architecture: How Manufacturing Methodologies Are Poised to Transform Building Construction (New York: McGraw Hill, 2004), xii.

5 Karl Wallick, Kieran Timberlake: Inquiry (New York: Rizzoli International Publications, 2011), 174.

6 Stephen Kieran and James Timberlake, Loblolly House: Elements of a New Architecture (New York: Princeton Architectural Press, 2008).

7 Ibid.

8 A popular US metal toy construction set introduced in the US in 1913 and still sold today.

9 Bruce Lindsey, Digital Gehry: Material Resistance, Digital Construction (Basel, Switz.: Birkhäuser Publishers for Architecture, 2001), 23-4.

10 Ibid., 23.

11 lbid., 35.

12 lbid., 35-37.

13 Philip Nobel, "Introduction", in SHoP: Out of Practice, Kimberley J. Holden et al., (New York: The Monacelli Press, 2012), 39-40.

14 Ibid., 38-39.

15 Kimberley J. Holden et al., SHoP: Out of Practice (New York: The Monacelli Press, 2012), 131.

16 Francesca Hughes, The Architecture of Error: Matter, Measure, and the Misadventures of Precision (Cambridge MA, USA: MIT Press, 2014), 12.

17 Dan Willis and Todd Woodward, "Diminishing Difficulty: Mass Customization and the Digital Production of Architecture", in Fabricating Architecture: Selected Readings in Digital Design and Manufacturing, Robert Corser, ed., (New York: Princeton Architectural Press, 2010), 184.

18 Nader Tehrani, Kirsten Giannattasio, and Heather Walls et al., "edge," in Immaterial/ Ultramaterial: Architecture, Design, and Materials, Toshiko Mori, ed., (Cambridge MA USA and New York: Harvard Graduate School of Design and Georges Braziller, Inc., 2002), 3.

Genevieve Baudoin is an Assistant Professor at the Department of Architecture, of the College of Architecture, Planning and Design at Kansas State University. Her background is as a cellist with a BA from Oberlin College, and she holds an MArch from the GSD at Harvard University. She has worked with Foster + Partners in London and Antoine Predock Architect in Albuquerque, NM. She is the author of Interpreting Site: Studies in Perception, Representation, and Design (Routledge, 2015). Her collaborative practice (Dual Ecologies), with designer Bruce Johnson, focuses on site and infrastructural relationships and their coincident architectural and tectonic response. E-mail: gbaudoin@ksu.edu 
